\title{
Las epidemias de erisipela en Chile
}

\author{
Enrique Laval $R$.
}

\section{Erysipelas outbreaks in Chile}

Historical antecedents of erysipelas outbreaks in Chile, registered by national bibliography at years 1822 and 1873 are reviewed. The first one, after an earthquake, with numerous severe ataxo-adynamic manifestations and the second, more attenuated with few severe cases. Remembers of treatments utilized at XIX Century for the disease and the beginning of sulphamides prescription at the thirty decade are presented. Afterwards penicillin and other antimicrobial agents treatments were implemented. Finally, we comment the severe presentation of soft tissues streptococcal diseases that appeared in the end of XX Century.

Key words: Erysipelas, outbreaks, Chile, emergent disease, severe manifestations.

Palabras clave: Erisipela, epidemias, Chile, enfermedad emergente, formas clínicas graves.
Pontificia Universidad Católica de Chile. Facultad de Medicina. Programa de Estudios Médicos Humanísticos.

Recibido: 18 de enero de 2011

Correspondencia a: Enrique Laval Román. revinf@sochinf.cl

\section{Introducción y antecedentes históricos}

L a erisipela fue conocida en tiempos de Hipócrates, atribuyéndola a "una mezcla de sangre y de bilis". Su descripción clínica fue precisada por Ambrosio Paré y Fabricio de Acquapendente. Sin embargo, a fines del siglo XVIII, a menudo se la confundía con otras dermatosis, época en que Velpeau y Trousseau, definieron su naturaleza infecciosa ${ }^{1}$.

Galeno estableció la distinción entre la erisipela y los flegmones, estimando que era debida a ciertas anomalías de la sangre, dependientes de trastornos de la función hepática.

En la Edad Media era costumbre considerar ocho enfermedades como contagiosas, de acuerdo con el verso citado por Bernardo de Gordon (1307):

"Febris acuta, ptisis, pedicon, scabies, sacer ignis, Antrax, liopa, lepra, nobis contagis praestant".

Estas ocho enfermedades, en orden correlativo, correspondían a: peste bubónica, tisis, epilepsia, sarna, erisipela, carbunco, tracoma y lepra.

Los pacientes con ellas, no eran recibidos en las ciudades, siendo aislados si se encontraban allí o arrojados fuera y no se les permitía vender artículos de consumo, como comidas o bebidas ${ }^{2,3}$.

Jerónimo Fracastoro (1478-1553), el gran médico renacentista, en el capítulo XV "De las diferentes especies de infecciones cutáneas, de su libro "Del contagio, de las enfermedades contagiosas y su curación", dice en parte "si hay bilis y es expulsada a la piel o está encerrada allá sin pudrirse, origina la enfermedad llamada erisipela, una o más pústulas acompañadas por un rubor y calor grande, y a veces fiebre. Si hay sangre en el compuesto, se llama erisipela flegmonosa, si pituita, erisipela edematosa, si atrabilis, erisipela escirrosa. En este tipo escirroso si la bilis amarilla es inflamada y encendida, produce un tipo de pústula llamada Epinyctis, debido a que muy a menudo, brota durante la noche. Cuando la erisipela es estática quema más, produciendo escamas y costras"4.
En Alemania Billroth y Volkmann (1869) sostuvieron que se trataba de un trastorno local dependiente de un veneno especial. Hueter pensó que podría deberse a la acción de un mismo organismo de la clase de las bacterias. La etiología no quedó definitivamente esclarecida sino hasta la era de Roberto Koch. Gracias a los métodos de este genial investigador, Fehleisen en 1883, consiguió probar que el agente patógeno era un estreptococo que se encuentra constantemente en las vías linfáticas de las zonas cutáneas enfermas, aislando dicha bacteria en cultivo puro, denominándolo Streptococcus erysipelatis y que era distinto del estreptococo piógeno, responsable de procesos supurativos, septicemia, etc.

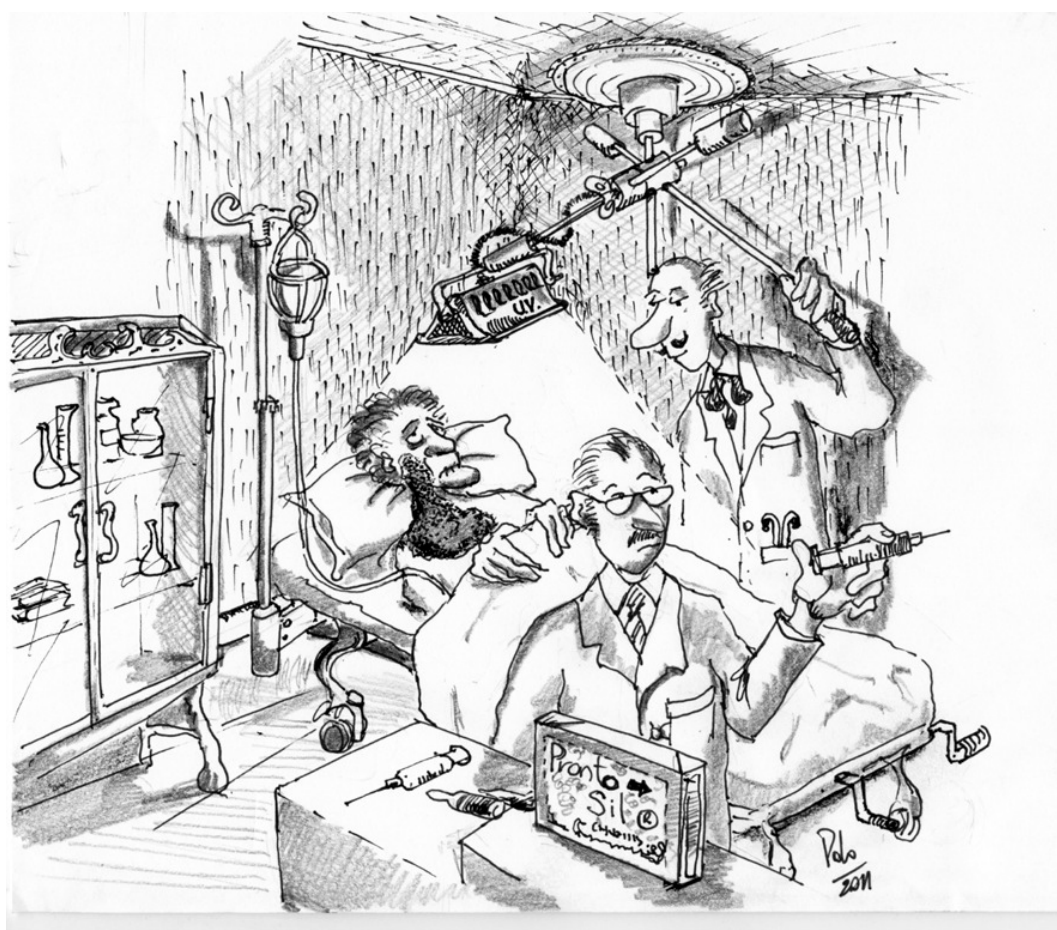


Para demostrar la identidad única de ambos, había que ocasionar erisipela típica en una persona, inoculándola con estreptococos de focos no erisipelatosos de otro individuo. Petruschy (1896) aportó esta prueba al inocular pus peritonítico a dos enfermos de cáncer, provocándoles erisipela. Tiempo después se comprobaría que la producción de distintos cuadros de infección, por un mismo estreptococo, dependería de los grados diferentes y variables de la virulencia del microorganismo, de la puerta de entrada e inmunidad previa del receptor ${ }^{2}$.

Hipócrates ya había mencionado la variedad traumática de la erisipela en relación con heridas de la piel, diferenciándola de la idiopática o de aparición espontánea.

La erisipela era una enfermedad de "hospital", muy frecuente en la época pre-antiséptica, causando epidemias en lazaretos, servicios de cirugía y gineco-obstétricos. El contagio se establecía por medio de los instrumentos y apósitos. Las manos del cirujano, de la matrona o enfermera eran portadoras de "gérmenes", que se depositaban a nivel de pequeñas heridas cutáneas, grietas de la piel o aun en el tegumento indemne. Desde la época de José Lister y de la cirugía aséptica esta complicación fue mucho menos frecuente 5 .

Es una lesión dolorosa con aspecto indurado ("piel de naranja"), edematosa, rojo brillante, localizándose en $70-80 \%$ de los pacientes en los miembros inferiores y en $5-20 \%$ en la cara. La fiebre es una característica.

La erisipela no complicada se mantiene confinada principalmente en los linfáticos y dermis ${ }^{6}$.

De todos los estreptococos, indiscutiblemente el beta hemolítico del grupo A (S. pyogenes), es el productor más importante de erisipela. Ha pasado por etapas en que se le ha menospreciado e incluso olvidado como agente de infecciones graves. Sin embargo, cada cierto tiempo se ha hecho presente mostrando su agresividad para provocar procesos a veces dramáticamente graves ${ }^{7}$.

\section{La erisipela en Chile.}

Epidemias (1822 y 1873)

En Chile, durante la colonia, no hubo referencias acerca de la existencia de epidemias de erisipela.

Según lo comunica el doctor Juan Miquel, a la Facultad de Medicina y de Ciencias Matemáticas y Físicas, el día 20 de noviembre de 1822, "Santiago sufrió una vez más los horrores de un violento terremoto y con mucha más vehemencia se sintió el sismo en varios puntos de la Republica, sobre todo en Valparaíso, Casablanca, Illapel, La Ligua, etc., los que fueron casi destruidos, pereciendo como 200 de sus habitantes". Sobrevino en la capital una epidemia de erisipela, de la cual dijo el doctor Miquel lo siguiente: "el influjo pernicioso del terremoto no se limitó a los trastornos mencionados; a las cuarenta y ocho horas después del horrible sacudimiento de tierra, empecé a reconocer en el hospital de mujeres que tenia exclusivamente a mi cargo, la modificación que en ciertas enfermas, tanto de medicina como de cirugía, en las que solo existían ante- riormente ligeras úlceras, a las doce horas de la invasión de escalofrios prolongados y seguidos de delirio, manchas erisipelatosas, partiendo siempre del punto desnudo del cutis y extendiéndose por todo el cuerpo. Esta erisipela corría sus periodos con una rapidez increíble y terminaba de ordinario en la gangrena que era la precursora de la muerte. Si se la aplicaba un cáustico, de el salian las primeras manchas de la erisipela; si se practicaba una operación, la erisipela invadía la herida. No se localizó solo en los hospitales esta destructora dolencia: en toda la ciudad se difundió con extrema velocidad y muy luego se vieron casos multiplicados de la erisipela negra, nombre con que el vulgo la denominaba; sesenta y siete señoras de estrado, de lo mas escogido de la sociedad fueron victimas de este terrible azote, las que tan luego como se embarazaban, sentían los síntomas de infección y en muy pocos días eran arrastradas al sepulcro y el tierno fruto de su unión generalmente las seguía, desenvolviéndose en él la enfermedad, en la herida hecha para separar el cordón umbilical y en las niñas por los agujeros que por costumbre se hacen en las orejas".

A raíz de esta epidemia (que continuó durante 1823, disminuyendo hasta desaparecer en 1826), el gobernador interino de Santiago, don Santiago Echevers, procurando combatirla, ordenó por bando del 27 de mayo de 1823, "que se blanqueara el exterior de las casas con cal, por ser esta sustancia el primer antídoto contra el mal, según lo decidido por una junta de médicos". Se dio el plazo de ocho días, bajo pena de 12 pesos de multa ${ }^{9}$.

Es posible que dicha medida pudiera haberse originado en un decreto del Director Supremo don Bernardo O’Higgins, ordenando al Protomédico doctor Eusebio Oliva "que celebre una junta de los mejores facultativos en Medicina y a la que concurrieran don Manuel Grajales, Agustín Nataniel Cox y don Juan Creus, para que traten de averiguar el origen de la introducción de la erisipela negra en el país"10.

Camilo Henríquez, en "El Mercurio de Chile”, No 5 de julio de 1823, publica algunas observaciones referente al Decreto anterior, dando cuenta de que hubo necesidad de hacer una reunión con los magistrados para que también se compenetrasen de la gravedad de la enfermedad, a la cual se remite de la siguiente manera y con cautela: "la enfermedad es contagiosa. En su fondo es una fiebre pútrida, en que la erisipela es un síntoma. Predomina en ella la diátesis asténica, que será un sinoco o un tifus más o menos terrible, según el grado de debilidad y las causas nocivas. Hasta ahora ha atacado a pocos. No es aún una epidemia y el pueblo no debe atemorizarse, pero tampoco descuidarse". Preguntaron una vez al célebre consejero Weikard acerca del medio más seguro para preservar al pueblo de una epidemia que se iba manifestando. El respondió: "cuidad de la limpieza pública y privada, es to es, de las calles, casas e individuos; haced que los habitantes tengan buen pan, buena carne, buen vino y anden abrigados. Entonces no hará progresos la epidemia"11. 
Creyéndose que el Tribunal del Protomedicato, con motivo de esta epidemia, no prestaba servicios, se decretó la formación de una "Junta de Sanidad" (1823). Componíase de 11 miembros, de los cuales dos eran médicos y sus atribuciones concernían con todo lo que se relacionaba con la higiene pública.A pesar de las esperanzas del Gobierno, la Junta de Sanidad nada hizo y fue desapareciendo a medida que pasaban las causas que la habían originado: viruela, erisipela negra y otras enfermedades. En 1826 se decretó su extinción y se creó en su lugar la "Sociedad Médica". Esta Sociedad (formada exclusivamente por todos los médicos) tuvo también corta existencia y fue reemplazada en 1827 por la "Inspección General de Medicina", la que no pudo ni siquiera establecerse. Mientras tanto las epidemias no habían cesado de presentarse en las desamparadas poblaciones de la República, sin que estas instituciones hubieran prestado el menor servicio a la salud pública ${ }^{9,11}$.

La escarlatina y la difteria, cuya primera epidemia se cree tuvo lugar en 1816, presentáronse en forma epidémica durante este período.

Fuera de aquellas enfermedades existían en los hospitales, "la erisipela, gangrena y piohemia", de tal modo, que habían peligros hasta en la más insignificante afección quirúrgica.

La influenza o gripe se mostró epidémica en 1831, 1832, 1846 y 1851 .

La infección purulenta y la gangrena de hospital, se presentaron en 1875 con los caracteres más malignos ${ }^{11}$.

La erisipela se transformó en una enfermedad endémica en Chile, pero en el mes de abril de 1873, se inició otra epidemia en Santiago. A medida que disminuían los casos de viruela, se multiplicaban los de erisipela, la que casi reinó sola durante los meses de julio y agosto del año ya mencionado. En septiembre disminuyó bastante y a principio de octubre sólo se conoció uno que otro enfermo.

Jerónimo Rosa Pizarro, alumno del $5^{\circ}$ año de Medicina, fue quien se refirió a esta epidemia de 1873, analizando 32 observaciones clínicas de los servicios de los doctores Wenceslao Díaz y Germán Schneider, más “unas pocas de la clientela particular de los doctores de la capital y que he podido seguir. La erisipela reinante, ha sido principalmente de la cara y más o menos benigna".

Lo que Rosa quiso resaltar es que "en esta epidemia no se haya presentado el gran contagio de que hablan algunos autores, si bien no se puede decir con esto, que no se hubieran producido algunos casos en que el contacto pareció evidente ya que en las 12 erisipelas que se han presentado en la clínica del doctor Wenceslao Díaz, cuatro solamente lo han sido como resultado de contagio o de infección manifiesta y siempre quedaron, de 29 enfermos que tiene esta sala, más de 25 indemnes en el transcurso de 4 meses. La clínica del doctor Germán Schneider que cuenta con 13 casos no tiene, sin embargo, ninguno desarrollado en la sala".

Pero lo que más le llamó la atención a Jerónimo Rosa, fue "que en la clínica quirúrgica donde no pasa un solo día en que no haya necesidad de algún golpe de bisturí, sin contar las operaciones de cirugía mayor, habiendo existido en la sala dos casos de erisipela de la cara y uno de un brazo, no tuvo que lamentarse el menor contagio". Los tres casos aparecidos posteriormente "ninguno fue efecto de contagio, pues no existía en la sala ningún caso en esa época, ni días antes de estas manifestaciones, a pesar de reinar la afección epidémicamente en la ciudad $y$ de tratarse de una sala de cirugía. Tampoco se conoció de un solo caso de contagio entre los individuos que están al servicio de los hospitales y en contacto directo con los enfermos".

Todo esto llevó a Jerónimo Rosa "a que han sido influenciados por una constitución médica reinante". Continúa citando a Reynaud, quien decía: "la erisipela unas veces es contagiosa y otras no, preguntándose si no existirán dos principios mórbidos distintos; uno dando lugar a la erisipela esporádica y el otro a la contagiosa".

Finalmente, hace hincapié en la recidiva de la enfermedad: "a mayor numero de ellas mayor gravedad en el pronóstico". De las cuatro recidivas observadas por él, "uno sucumbió con síntomas ataxo-adinámicos arrastrados por una meningitis; otros con dos recidivas hizo temer por su vida a causa de los síntomas tifoideos que se presentaron". Lo mismo del tercer enfermo debido a la intensidad de la fiebre. En el cuarto, habiendo tenido dos recidivas, los ataques fueron cada vez más benignos ${ }^{12}$.

Jerónimo Rosa Pizarro se tituló de médico el 24 de agosto de 1875. En 1876, fue ayudante en la Clínica Médica del profesor Wenceslao Díaz y en diciembre de ese año, comisionado para combatir la viruela en Chiloé. Durante la guerra contra Perú y Bolivia, en octubre de 1879 , fue designado cirujano $1^{\circ}$ del Regimiento de Línea $\mathrm{N}^{\circ} 3$. En enero de 1881, sirvió como cirujano adjunto del Ejército de Operaciones, siendo destinado al Hospital Guadalupe del Callao, Perú. Ejerció como médico de vacuna en Angol, desde 1893 a 1896. En 1901 se hizo cargo de las salas San Vicente y Santa Filomena del Hospital San José de Santiago. Falleció el 26 de septiembre de $1913^{13}$

\section{Tratamiento de la erisipela en el siglo XIX}

Habría que referirse a la tesis manuscrita del doctor Arcadio Cerda Núñez, del año 1885, "De los diversos medicamentos empleados contra la erisipela", que se encuentra en la biblioteca del Museo Nacional de la Medicina. Comienza diciendo "que la erisipela es una enfermedad demasiado conocida para que la describa. Sólo diré cuatro palabras sobre su etiología con el objeto de deducir en mis conclusiones el tratamiento más racional, aquel que obrando sobre la causa misma de la enfermedad puede atacarla con provecho, ya que aún no se ha encontrado al agente que la distinga".

Cerda escribe "que la naturaleza séptica de la erisipela se haya comprobada en el estudio de las epidemias, por su contagio evidente, por limitarse aquellas a lugares 
definidos y aparecer en circunstancias atmosféricas más o menos especiales, como sucedió en la primera epidemia de erisipela en los Estados Unidos de Norteamérica, 1843 a 1847, en que se demostró su origen especifico. Hay un hecho práctico innegable que es la desaparición de esta enfermedad, podemos decir completa, en las salas de cirugía que se usan para la curación de toda clase de heridas con tratamientos antisépticos enérgicos".

Desde hace mucho tiempo se ha hablado de la coincidencia de las epidemias de erisipela con las de fiebre puerperal, por lo que hoy muchos ven en esto una sola entidad morbosa. Pouteau en 1750, fue el primero en afirmar que la "fiebre puerperal era la erisipela del peritoneo". Hay entidad de naturaleza entre la erisipela y la septicemia, ya sea puerperal o quirúrgica. La erisipela, no siendo más que "una de las expresiones de la septicemia, puede engendrar por contagio esta última. De tal manera que las mismas medidas preventivas deben tenerse presentes para ambas".

Ahora bien, "las prolijas investigaciones de los micrógrafos modernos han demostrado que todas las enfermedades contagiosas e infecciosas están bajo la dependencia de un germen específico orgánico, de tal manera que todo hace suponer la presencia de un microorganismo en el veneno virus erisipelatoso".

Detalla Cerda las medidas terapéuticas locales y generales a emplear: "las cataplasmas de féculas, polvos emolientes, cáusticos, el frío, pomadas, el colodión, cloroformo, alcanfor, esencia de trementina, vino de quina, etc.".

"Que no siendo bien establecida hasta hoy la eficacia y ¿segura? de ninguno de los medicamentos en uso, la medicación expectante e inteligente debe ser la ordinaria en las erisipelas leves.

En las graves y en todas las que se quiera usar un medicamento, el sulfato de quinina es el que mejor responde a las indicaciones que deben llenarse con la medicación interna. Esta puede usarse tanto en la erisipela traumática como en la médica, estando conforme con todas las causas específicas de la afección" ${ }^{14}$.

La terapia de la erisipela continuó con muy escasas variaciones durante el siglo XIX. Debove y Achard, seguían preconizando un tratamiento local con pomadas, compresas y pulverizaciones calientes de licor de Van Swieten (solución alcohólica de sublimado corrosivo al 1 x 1.000). Para impedir la extensión de la placa de erisipela, indicaban circunscribir el rodete con pulverizaciones de una solución etérea de sublimado al 1 x 100, o por un blanqueamiento con una preparación de ictiol y traumaticina, o bien, con ácido fénico y alcohol de $90^{\circ}$. De las pomadas, la más usada era la de salol o resorcina, lanolina y vaselina; las compresas húmedas podían tener salicilato de soda y agua destilada, o bien, sublimado, ácido tartárico y también agua destilada.

En el tratamiento general, se utilizaba como antifebril el sulfato de quinina y antipirina. Se recomendaba además la hidroterapia y tónicos, como el extracto de quinina y la poción de Todd, que era un tónico estimulante, muy empleado en la neumonía, compuesto de alcohol de $60^{\circ}$, agua de hisopo y jarabe discodión. El hisopo debe su nombre a una planta de la familia de las labiadas (Hyssopus officinalis), cuyas hojas y flores son aromáticas, estimulantes, antitusígenas y tónicas. (15)

En los primeros años del siglo XX, se incorporaron nuevos tratamientos. Así se menciona una experiencia de A. Bongio, que trató tres enfermos de erisipela de la cara con aplicaciones locales de suero antidiftérico, cuyos resultados los consideró "muy netos". Nobécourt, en París, señaló "los buenos efectos" que obtuvo con el tratamiento por las pincelaciones con una solución acuosa de azul de metileno al 5\%, de la placa de erisipela ${ }^{16,17}$.

En Chile, González von Marees y Alessandrini comunicaron haber utilizado luz ultravioleta en una enferma con erisipela de la cara, en que irradiaron la placa, durante 10 minutos, a una distancia de $30 \mathrm{~cm}$. Al día siguiente estaba afebril y la placa presentaba "el aspecto de una quemadura de luz ultravioleta". Según el profesor Deneke de Hamburgo, la "aplicación de luz ultravioleta constituye la terapéutica de elección en todo caso de erisipela"18.

J.P.Tournex, también en París, relata "los excelentes resultados que le ha procurado la vacunoterapia con la vacuna antipiógena polivalente de Bruschettini, en dos casos de erisipela". A las 48 horas de la segunda inyección desapareció el alza febril; después de la quinta inyección, ya no había los signos de la infección ${ }^{10}$.

\section{Introducción de los antimicrobianos en el siglo XX. Aparición de cuadros graves de erisipela en la década de los 80}

En 1937, la Revista Médica de Chile, da a conocer las experiencias en Alemania, del doctor Karl Hattl (tratamiento de la erisipela en adultos por Prontosil ${ }^{\circledR}$ ) y la del doctor Virgilio Anghelescu (investigación comparada sobre sueroterapia, aplicaciones de luz ultravioleta y quimioterapia en la erisipela).

En ambas investigaciones se utilizó Prontosil ${ }^{\circledR}$, que es el nombre patentado de una sulfonamida, sulfapiridina, sustancia antiséptica anti-estreptocóccica obtenida por Domagk. En realidad, fue el primer sulfamidado empleado en la terapia antimicrobiana.

En la serie del doctor Hattl, que usó Prontosil ${ }^{\circledR}$ por vía intravenosa y oral, no se observó diferencias importantes con los que no recibieron el medicamento. En cambio, los enfermos del doctor Anghelescu que se trataron con Prontosil ${ }^{\circledR}$, tuvieron resultados bastante favorables. Hubo fracaso total en los que se empleó, exclusivamente suero anti-estreptocóccico ${ }^{20-22}$.

Con la introducción de la penicilina, en la década de 1940, las infecciones graves estreptocóccicas, llegaron a ser casi excepcionales, pensando algunos que estaban en franca extinción. Como lo señala Alberto Fica "debido a que los cuadros de erisipela no se asocian, en general, a estreptococos resistentes a diferentes antimicrobianos, utilizados posteriormente, esta enfermedad puede ser universalmente tratada con penicilina, derivados $u$ otros, 
cloxacilina, eritromicina, amoxicilina, amoxicilina/ácido clavulánico, clindamicina, cefazolina"23.

No he encontrado comunicaciones o publicaciones sobre epidemias de erisipela en Chile, en el siglo XX y en lo que va corrido del siglo XXI.

Los ya citados, González von Marees y Alessandrini, pensaban en 1929, que el tratamiento de la erisipela de la cara con luz ultravioleta "podría beneficiar a los muchísimos enfermos que actualmente hay con erisipela" ${ }^{18}$. Ese año, eso sí, hubo una importante epidemia de escarlatina en Chile ${ }^{24}$.

Al igual que en otras partes del mundo, más o menos desde 1984, pero sobre todo durante 1986, se comprobó en diferentes centros asistenciales chilenos, un aumento de diversas estreptococcias cutáneas, con la sorprendente aparición de procesos gravísimos necróticos de tejidos blandos y septicemias similares a las descritas hace varias décadas.

La experiencia que se tuvo con la erisipela, en el Hospital de Enfermedades Infecciosas Prof. Dr. Lucio Córdova, de Santiago, entre 1977 y 1993, conviene recordarla.

Entre 1977 y 1984, hubo un número más o menos constante, entre 30 y 40 casos anuales de erisipela pero, a partir de 1985 y sobre todo en 1986, se produjo una explosión violenta de dicha estreptococcia, llegando a 117 enfermos. Durante el año 1987 esta tendencia se mantuvo, incluso aumentó, habiéndose atendido 149 pacientes. No sólo hubo una mayor consulta, sino que se comprobó cuadros graves de erisipela, complicados de flegmones o abscesos, con compromiso del estado general y síndrome febril importante. A partir de aquel año disminuyó el número de enfermos, pero estabilizándose a un nivel superior al observado antes de $1985^{7}$.

\section{Resumen}

Se revisa los antecedentes históricos de las epidemias de erisipela en Chile, que anota la bibliografía nacional, en los años 1822 y 1873 . La primera, a continuación de un terremoto, con numerosas formas graves ataxoadinámicas y la segunda, más benigna, con pocos casos graves. Se recuerda los tratamientos de la enfermedad utilizados en el siglo XIX y la iniciación de los antimicrobianos sulfamidados, en la década de los años 30. Posteriormente penicilina y otros antimicrobianos. Finalmente, se comenta la gravedad emergente de las infecciones estreptocóccicas de tejidos blandos, en los últimos años del siglo XX.

\section{Referencias}

1.- Laignel - Lavastine. Histoire Génerale de la Médicine. Tomo III. Ed. Albin Michel. París. Francia. (Sin año)

2.- Von Bergmann, G. Tratado de Medicina Interna. Ed. Labor. Barcelona. España. 1942.

3.- Harrison F H. Historia de la Medicina, Ed. Interamericana. Méjico. 1966.
4.- Fracastoro J. Del contagio, de las enfermedades contagiosas y su curación. Cap. XV. De las diferentes especies de infecciones cutáneas. Colección de clásicos de la Medicina. 1962.

5.- Pedro-Pons A. Tratado de Patología y Clínica Médicas. Tomo VI. Enfermedades Infecciosas. Ed. Salvat. Barcelona. España. 1952.

6.- Mandell G L, Gordon Douglas R, Bennett J E. Enfermedades Infecciosas, Principios y Práctica. $3^{\text {a }}$ Edición. Ed. Panamericana. Bs Aires. República Argentina. 1990.

7.- Laval R E. La infección por el estreptococo beta hemolítico del grupo A: ¿vuelta al pasado? Rev Chile Infect 1994; 11 : 73-81.

8.- Miquel J. Apuntes sobre el terremoto de 1822. AUCH. 1859. p. 228-33.

9.- Ferrer P L. Historia de la Medicina en Chile. Tomo I. Impta. Talca. Chile. 1904.

10.- Decreto del Director Supremo don Bernardo O'Higgins, para que una junta de médicos logre averiguar el origen de la epidemia de erisipela negra. Gazeta Ministerial de Chile. Tomo III. No 50.10 de julio de 1823.

11.- Salas Olano E. Historia de la Medicina en Chile. Impta. Vicuña Mackenna. Santiago de Chile. 1894.

12.- Rosa P J. Epidemia de erisipela. Rev Méd Chile 1873-74; 2 : 145-55.

13.- Laval M E. Biografías de médicos en Chile. Siglo XIX (inédito)

14.- Cerda N A. De los diversos medicamentos empleados contra la erisipela 1885. Tesis manuscrita. Biblioteca del Museo Nacional de la Medicina. Universidad de Chile. Facultad de Medicina.

15.- Debove G M, Achard Ch. Manuel de Médicine. Tomo IX. Maladies Infectieeuses. Ed. Rueff et Cie. París. Francia. 1897.

16.- Bongio A. Tres casos de erisipela de la cara tratados por aplicaciones locales de suero anti-diftérico. Rev Méd Chile 1907; 35: 302-03. (Revista extranjera).

17.- Nobécourt M. Tratamiento de la erisipela de la cara por las pincelaciones por azul de metileno. Rev Méd Chile 1916; 44: 352. (Revista extranjera).

18.- González V M, Alessandrini I. Erisipela de la cara tratada con luz ultravioleta. Bol Soc Cir Chile 1929; 7: 139-41.

19.- Torneux J P. Vacunoterapia en la erisipela. Rev Méd Chile 1929; 57: 435. (Revista extranjera).

20.- Cardenal L. Diccionario terminológico de ciencias médicas. Salvat Edit. Barcelona. España. 1947.

21.- Hartl K. Tratamiento de la erisipela en adultos por Prontosil. Rev Méd Chile 1937; 65: 42-3. (Revista extranjera).

22.- Anghelescu V. Investigación comparada sobre sueroterapia, aplicaciones de luz ultravioleta y quimioterapia en la erisipela. Ibid. p. 43.

23.- Fica C A. Celulitis y erisipela: manejo en atención primaria. Rev Chile Infect 2003; 20: 104-10.

24.- Laval R E. La epidemia de escarlatina del año 1929 en Chile. Rev Chile Infect 2009; 26: 168-72. 